\title{
Effect of ozone oxidative preconditioning in preventing early radiation-induced lung injury in rats
}

\author{
B.H. Bakkal ${ }^{1}$, F.A. Gultekin ${ }^{2}$, B. Guven ${ }^{3}$, U.O. Turkcu ${ }^{4}$, S. Bektas ${ }^{5}$ and M. Can $^{3}$ \\ ${ }^{1}$ Department of Radiation Oncology, School of Medicine, Bulent Ecevit University, Kozlu, Zonguldak, Turkey \\ ${ }^{2}$ Department of General Surgery, School of Medicine, Bulent Ecevit University, Kozlu, Zonguldak, Turkey \\ ${ }^{3}$ Department of Biochemistry, School of Medicine, Bulent Ecevit University, Kozlu, Zonguldak, Turkey \\ ${ }^{4}$ Mugla School of Health Sciences, Mugla Sitki Kocman University, Mugla, Turkey \\ ${ }^{5}$ Department of Pathology, School of Medicine, Bulent Ecevit University, Kozlu, Zonguldak, Turkey
}

\begin{abstract}
lonizing radiation causes its biological effects mainly through oxidative damage induced by reactive oxygen species. Previous studies showed that ozone oxidative preconditioning attenuated pathophysiological events mediated by reactive oxygen species. As inhalation of ozone induces lung injury, the aim of this study was to examine whether ozone oxidative preconditioning potentiates or attenuates the effects of irradiation on the lung. Rats were subjected to total body irradiation, with or without treatment with ozone oxidative preconditioning $(0.72 \mathrm{mg} / \mathrm{kg})$. Serum proinflammatory cytokine levels, oxidative damage markers, and histopathological analysis were compared at 6 and $72 \mathrm{~h}$ after total body irradiation. Irradiation significantly increased lung malondialdehyde levels as an end-product of lipoperoxidation. Irradiation also significantly decreased lung superoxide dismutase activity, which is an indicator of the generation of oxidative stress and an early protective response to oxidative damage. Ozone oxidative preconditioning plus irradiation significantly decreased malondialdehyde levels and increased the activity of superoxide dismutase, which might indicate protection of the lung from radiation-induced lung injury. Serum tumor necrosis factor alpha and interleukin-1 beta levels, which increased significantly following total body irradiation, were decreased with ozone oxidative preconditioning. Moreover, ozone oxidative preconditioning was able to ameliorate radiation-induced lung injury assessed by histopathological evaluation. In conclusion, ozone oxidative preconditioning, repeated low-dose intraperitoneal administration of ozone, did not exacerbate radiation-induced lung injury, and, on the contrary, it provided protection against radiation-induced lung damage.
\end{abstract}

Key words: Ozone oxidative preconditioning; Irradiation; Lung injury

\section{Introduction}

Whole body exposure to ionizing radiation (IR) may trigger in humans and animals multiple organ dysfunction directly related to an increase in cellular oxidative stress due to overproduction of reactive oxidative species (ROS) from molecular ionization $(1,2)$. A large number of studies have indicated that DNA, lipids, and proteins are attacked by free radicals induced by IR, thereby leading to significant cellular damage (3). Additionally, ROS also negatively impact the antioxidant defense mechanisms, reduce the intracellular concentration of glutathione (GSH), and decrease the activities of superoxide dismutase (SOD), catalase (CAT), and glutathione peroxidase (GSHPx). Thus, the organs become more susceptible to the deleterious effects of ROS (4). Therefore, any agent exhibiting antioxidant effects can help protect cells from radiation toxicity.

Many controlled trials have examined the validity of using ozone as a therapeutic agent for the treatment of several disorders (5). Ozone administration has been shown to exert a protective effect against liver damage induced by carbon tetrachloride and against renal ischemic-reperfusion injury by an oxidative preconditioning mechanism that stimulates antioxidant endogenous systems and modulates nitric oxide production (6). The term "ozone oxidative preconditioning" (OOP) refers to the administration of ozone at repeated nontoxic doses that provide an adaptation to oxidative stress. Adaptation occurs through the induction of enzymes or by activating

Correspondence: B.H. Bakkal, Department of Radiation Oncology, School of Medicine, Bulent Ecevit University, Kozlu, Zonguldak 67600, Turkey. Fax: +90-372-261-0155. E-mail: bhbakkal@yahoo.com 
metabolic pathways that maintain an equilibrated redox balance, such as induction of SOD, increase in GSH levels, and lowered peroxidation (7). Moreover, ozone could prepare the host for the physiopathological conditions mediated by ROS (8). In a previous study, we demonstrated that OOP could increase the endogenous antioxidant defense mechanism and induce an adaptation to oxidative stress in rats, and thereby protect the animals from radiation-induced hepatic and ileal injury (9). Although atoxic doses of ozone prevent radiation-induced organ damage, ozone itself is a pulmonary irritant known to cause oxidative stress, inflammation, and tissue injury (10).

We hypothesize that ozone is one of the driving forces in initiating oxidative stress, inflammation, and lung injury. Therefore, the goal of this study was to determine, using a rat model of radiation-induced lung injury (RILI), the effects of repeated intraperitoneal (ip) injections of ozone on the lung before total body irradiation (TBI) and to determine whether OOP potentiates the effects of IR or attenuates its effects by increasing the endogenous antioxidant system.

\section{Material and Methods}

The experimental protocols were conducted with the approval of the Animal Research Committee at Bulent Ecevit University, Zonguldak, Turkey. All animals were maintained in accordance with the recommendations of the National Institutes of Health Guidelines for the Care and Use of Laboratory Animals.

\section{Animals and experimental procedures}

Forty female Wistar rats weighing 200-230 g were housed individually in cages and were allowed free access to standard rat chow and water before and after the experiments. The animal rooms were windowless with temperature $\left(22 \pm 2^{\circ} \mathrm{C}\right)$ and lighting controls. The animals were fasted overnight before the experiments but were given free access to water. They were anesthetized with $100 \mathrm{mg} / \mathrm{kg}$ ketamine and $20 \mathrm{mg}$ xylazine/kg body weight ip.

The rats were divided into five equal groups. In the control group (group 1), animals received daily ip injections of $0.9 \%$ saline for 5 days. In the saline-treated and IR groups (groups 2 and 3 ), animals received daily ip injections of $0.9 \%$ saline for 5 days. One hour after the last injection of saline, the animals were exposed to a dose of 6 Gy TBI. Rats were decapitated at 6 h (group 2) and 72 h (group 3) after exposure to radiation. In OOP and IR groups (groups 4 and 5), an ozone/oxygen mixture was administered ip at a dose of $0.7 \mathrm{mg} / \mathrm{kg}$. The volume of gaseous mixture administered to each animal was approximately $2.3 \mathrm{~mL}$. OOP was performed using 5 applications (once daily) of the ozone/oxygen mixture. One hour after the last injection, the rats were irradiated with $6 \mathrm{~Gy} \mathrm{TBI}$ in a single fraction. Rats were decapitated at $6 \mathrm{~h}$ (group 4) and $72 \mathrm{~h}$ (group 5) after the exposure to radiation.

\section{Ozone production}

Ozone was generated by an ozone generator, which allowed control of the gas flow rate and ozone concentration in real time using a built-in ultraviolet spectrometer and was administrated immediately at a dose of $0.72 \mathrm{mg} / \mathrm{kg}$ daily via an ip route. The volume of the injected mixture was approximately $2.3 \mathrm{~mL}$. Oxidative preconditioning was performed using 5 applications (once daily) of the ozone/oxygen mixture. The ozone flow rate was kept constant at $3 \mathrm{~L} / \mathrm{min}$, representing a concentration of $60 \mathrm{mg} / \mathrm{mL}$ and a gas mixture of $97 \%$ oxygen $+3 \%$ ozone. Tygon polymer tubes and single-use silicone-treated polypropylene syringes (ozone resistant) were used throughout the experiment to ensure containment of ozone and consistency of concentration $(11,12)$.

\section{Total body irradiation}

Computerized tomography simulation of rats was performed with 1-mm slices, and a dose calculation was performed with the Eclipse treatment planning system version 8.9 (Varian Medical Systems, USA). TBI was delivered to anesthetized (ketamine $100 \mathrm{mg} / \mathrm{kg}$ intramuscular injection) rats in the prone position with a single non-lethal dose of 6 Gy using a 6-MV linear accelerator (Varian Medical Systems) at a dose rate of approximately $1 \mathrm{~Gy} / \mathrm{min}$ with the source axis distance technique and a $1.0-\mathrm{cm}$ bolus material on the surface. Animals were returned to their home cages following irradiation. Control animals were anesthetized but were not exposed to radiation. All irradiations were performed between 7:00 and 8:30 am.

\section{Sample collection}

At the end of the experimental period, all animals were killed. Trunk blood was collected for tumor necrosis factor alpha $(T N F-\alpha)$ and interleukin-1beta (IL-1 $\beta)$. Tissue samples from the lung were fixed in formaldehyde for histological analysis, while additional samples were stored at $-80^{\circ} \mathrm{C}$ for the determination of malondialdehyde (MDA) levels and SOD activity.

\section{Biochemical analysis}

TNF- $\alpha$ and IL-1 $\beta$ were assayed in serum samples for the evaluation of generalized tissue damage. Serum IL-1 $\beta$ levels were measured using enzyme-linked immunosorbent assay (ELISA) according to the manufacturer's instructions (Bendermed International, Inc., USA). The levels of IL-1 $\beta$ were calculated from a standard curve and are reported as $\mathrm{pg} / \mathrm{mL}$. Serum TNF- $\alpha$ levels were measured using rat commercial ELISA reagents (eBioscience, USA) following the manufacturer's protocol. The results are reported as $\mathrm{pg} / \mathrm{mL}$ for TNF- $\alpha$. Lung tissues were homogenized in 10 volumes of $150 \mathrm{mM}$ ice-cold $\mathrm{KCl}$ using a glass Teflon 
homogenizer (Ultra Turrax IKA T18 Basic, Germany), after cutting the tissue into small pieces with scissors (for 2 min at $5000 \mathrm{rpm}$ ). The homogenate was then centrifuged at $5000 \mathrm{~g}$ for $15 \mathrm{~min}$ and the supernatant used for analysis. High-performance liquid chromatographic (HPLC) analysis was performed with the isocratic method using an Agilent 1200 HPLC system (USA) with a commercial MDA kit (Immundiagnostik AG, Germany). The first step in determining MDA was sample preparation with a derivatization reagent that transforms MDA into a fluorescent product. Afterwards, the $\mathrm{pH}$ was optimized and the reaction mixture $(20 \mathrm{~mL})$ was chromatographed on a reverse-phase C18 column $(18.5 \mathrm{~mm}, 125 \times 4 \mathrm{~mm})$ at $30^{\circ} \mathrm{C}$. The flow rate was $0.8 \mathrm{~mL} / \mathrm{min}$. Fluorimetric detection was performed with excitation at $515 \mathrm{~nm}$ and emission at $553 \mathrm{~nm}$. The detection limit was $0.15 \mathrm{mM}$, and linearity was up to $100 \mathrm{mM}$. Protein concentrations of the supernatants were determined by the Lowry method (13). Total SOD activity was determined according to the method of Sun et al. (14). The principle behind that method was based on inhibition of nitroblue tetrazolium (NBT) reduction by a xanthinexanthine oxidase system as a superoxide generator. Activity was assessed in the ethanol phase of the liver homogenate after a 1.0-mL ethanol/chloroform mixture $(5: 3, v / v)$ was added to the same volume of the hemolysate and centrifuged. One unit of SOD was defined as the amount of enzyme causing $50 \%$ inhibition of the NBT reduction rate. Results are reported as $\mathrm{nmol} / \mathrm{g}$ protein for MDA and as $U / g$ protein for SOD.

\section{Histopathological analysis}

The lung tissue samples were fixed in $10 \%$ buffered formalin solution, embedded in paraffin, and cut into $5-\mu \mathrm{m}$ sections. The sections were stained with hematoxylineosin and examined under a light microscope by a blinded pathologist. Sections were visualized under a Zeiss Imager A2 (Germany).

\section{Statistical analysis}

Statistical analysis was conducted with the SPSS version 13.0 software package (IBM, USA). Continuous variables were given with mean, median, standard deviation, minimum, and maximum values. Normality analyses were performed using the Shapiro-Wilk test in order to evaluate the distribution of the data. Dual and triple comparisons among groups were then performed by the Mann-Whitney U-test and the Kruskal-Wallis test, respectively. $P$ values $<0.05$ were considered to be statistically significant.

\section{Results}

\section{Biochemical analysis}

ELISA analysis indicated that animals in the irradiated group had significantly increased serum TNF- $\alpha$ and IL-1 $\beta$ at both 6 and $72 \mathrm{~h}$ post-irradiation compared to control animals $(P=0.001)$. OOP reversed these changes
Table 1. Serum TNF- $\alpha$ levels of control, saline-treated $+I R$, or $\mathrm{OOP}+\mathrm{IR}$ groups decapitated at 6 or $72 \mathrm{~h}$ after irradiation.

\begin{tabular}{lcc}
\hline Groups & \multicolumn{2}{c}{ Median serum TNF- $\alpha$ levels, } \\
\cline { 2 - 3 } & $\begin{array}{c}\mathrm{pg} / \mathrm{mL} \\
\text { (min-max) }\end{array}$ & $\begin{array}{c}95 \% \mathrm{Cl} \\
\text { (lower-upper) }\end{array}$ \\
\hline $\begin{array}{l}\text { Control (group 1)* } \\
\begin{array}{l}\text { Saline-treated + IR 6 h } \\
\text { (group 2) }\end{array}\end{array}$ & $33.40(27.20-36.50)$ & $30.48-34.45$ \\
$\begin{array}{l}\text { Saline-treated + IR 72 h } \\
\text { (group 3) }\end{array}$ & $64.65(54.90-75.50)$ & $60.04-68.72$ \\
OOP + IR 6 h (group 4) & $48.30(41.90-59.10)$ & $45.80-53.99$ \\
OOP + IR 72 h (group 5) & $46.40(39.80-58.30)$ & $43.18-50.34$ \\
\hline
\end{tabular}

TNF- $\alpha$ : tumor necrosis factor alpha; IR: ionizing radiation; OOP: ozone oxidative preconditioning. ${ }^{*} \mathrm{P}=0.001$ (Kruskall-Wallis test).

significantly $(P=0.001$; Tables 1 and 2$)$. The outcomes of these proinflammatory parameters are presented in Figures 1 and 2.

The effects of TBI at $6 \mathrm{~h}$ after IR caused a statistically insignificant increase in pulmonary MDA levels $(P=0.145$; Table 3), whereas values for lung MDA levels in the IR groups were still found to be higher compared to the control group. These levels peaked at $72 \mathrm{~h}$ after IR in all irradiated groups. OOP more effectively inhibited these irradiation-induced elevations in lung MDA levels at $72 \mathrm{~h}$ after irradiation compared to the radiation alone group $(P=0.001$; Figure 3$)$. SOD activity in lung tissues significantly decreased at 6 and $72 \mathrm{~h}$ following irradiation, compared to the control group $(P=0.001)$. OOP significantly reversed lung SOD activity back to control values $(P=0.001$; Figure 4 and Table 4).

\section{Histopathological analysis}

On histopathological examination, no abnormalities were seen in the lungs of the control group animals

Table 2. Serum IL-1 $\beta$ levels of control, saline-treated $+I R$, or $\mathrm{OOP}+\mathrm{IR}$ groups decapitated at 6 or $72 \mathrm{~h}$ after irradiation.

\begin{tabular}{|c|c|c|}
\hline \multirow[t]{2}{*}{ Groups } & \multicolumn{2}{|c|}{ Median serum IL-1 $\beta$ levels } \\
\hline & $\underset{(\min -m a x)}{\mathrm{pg} / \mathrm{mL}}$ & $\begin{array}{c}95 \% \mathrm{Cl} \\
\text { (lower-upper) }\end{array}$ \\
\hline Control (group 1)* & $151.50(134.00-186.00)$ & $143.50-165.49$ \\
\hline $\begin{array}{l}\text { Saline-treated + IR } \\
6 \mathrm{~h} \text { (group 2) }\end{array}$ & $250.00(222.00-294.00)$ & 239.25-270.74 \\
\hline $\begin{array}{l}\text { Saline-treated + IR } \\
72 \text { h (group 3) }\end{array}$ & $290.50(268.00-306.00)$ & 279.00-295.62 \\
\hline $\begin{array}{l}\mathrm{OOP}+\mathrm{IR} 6 \mathrm{~h} \\
\text { (group 4) }\end{array}$ & $216.00(198.00-231.00)$ & 206.12-221.12 \\
\hline $\begin{array}{l}\text { OOP + IR } 72 \text { h } \\
\text { (group 5) }\end{array}$ & $202.00(162.00-220.00)$ & 185.75-208.25 \\
\hline
\end{tabular}

IL-1 $\beta$ : interleukin-1 $\beta$; IR: ionizing radiation; OOP: ozone oxidative preconditioning. ${ }^{*} \mathrm{P}=0.001$ (Kruskall-Wallis test). 


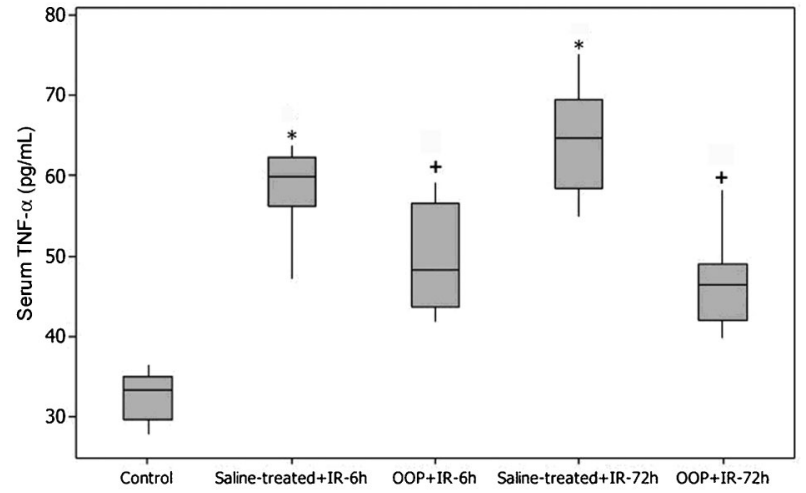

Figure 1. Serum tumor necrosis factor alpha (TNF- $\alpha$ ) levels of control, saline-treated + ionizing radiation (IR), or ozone oxidative preconditioning (OOP) + IR groups decapitated at 6 or $72 \mathrm{~h}$ after irradiation. Each group consisted of 8 rats. ${ }^{*} \mathrm{P}=0.001$ compared to control group; ${ }^{+} \mathrm{P}=0.001$ compared to saline-treated group (Mann-Whitney U-test).

(Figure 5A). Alveolar area reduction as well as alveolar and bronchiolar hemorrhage were observed in the lung tissues of the radiation-treated group at $6 \mathrm{~h}$ (Figure 5B). Severe alveolar and bronchiolar hemorrhage, alveolar area reduction, interstitial congestion, and edema were more prominent in the radiation-treated group at $72 \mathrm{~h}$ (Figure $5 \mathrm{C}$ ). In the ozone-treated groups at 6 and $72 \mathrm{~h}$, alveolar area reduction, interstitial congestion, and alveolar and bronchiolar hemorrhage were reduced compared with the radiation-treated groups at 6 and $72 \mathrm{~h}$ (Figure 5D and E).

\section{Discussion}

A gas mixture containing ozone/oxygen used in medicine is known as medical ozone therapy. Clinical

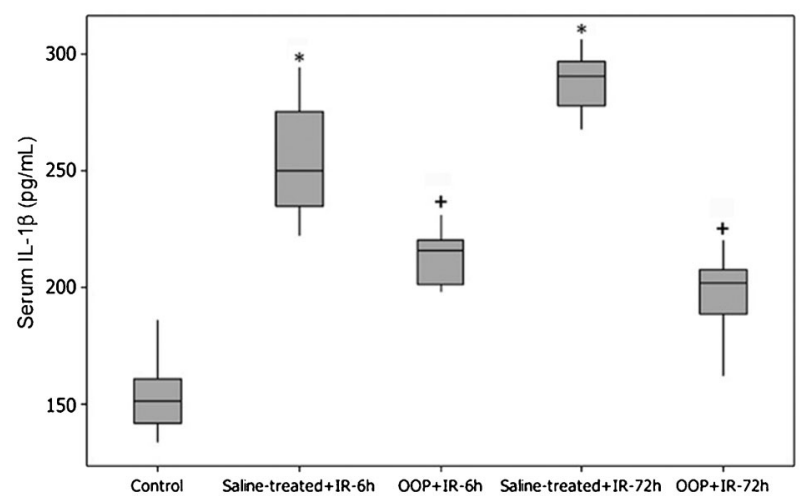

Figure 2. Serum interleukin-1 $\beta$ (IL-1 $\beta$ ) levels of control, salinetreated + ionizing radiation (IR), or ozone oxidative preconditioning $(\mathrm{OOP})+\mathrm{IR}$ groups decapitated at 6 or $72 \mathrm{~h}$ after irradiation. Each group consisted of 8 rats. ${ }^{*} P=0.001$ compared to control group; ${ }^{+} \mathrm{P}=0.001$ compared to saline-treated group (MannWhitney U-test).
Table 3. Tissue MDA levels of control, saline-treated $+I R$, or $\mathrm{OOP}+\mathrm{IR}$ groups decapitated at 6 or $72 \mathrm{~h}$ after irradiation.

\begin{tabular}{lcc}
\hline Groups & \multicolumn{2}{c}{ Median tissue MDA levels } \\
\cline { 2 - 3 } & $\begin{array}{c}\mathrm{nmol} / \mathrm{g} \\
\text { (min-max) }\end{array}$ & $\begin{array}{c}95 \% \mathrm{Cl} \\
\text { (lower-upper) }\end{array}$ \\
\hline $\begin{array}{l}\text { Control (group 1) } \\
\text { Saline-treated + IR 6 h }\end{array}$ & $4.07(3.32-5.32)$ & $3.72-4.52$ \\
(group 2) & $4.12(3.59-5.99)$ & $3.99-5.05$ \\
$\begin{array}{l}\text { Saline-treated + IR 72 h } \\
\text { (group 3) }\end{array}$ & $8.52(7.07-10.39)$ & $7.89-9.35$ \\
OOP + IR 6 h (group 4) & $4.94(3.40-5.32)$ & $4.39-5.15$ \\
OOP + IR 72 h (group 5) & $5.87(5.25-6.73)$ & $5.60-6.36$ \\
\hline
\end{tabular}

MDA: malondialdehyde; IR: ionizing radiation; OOP: ozone oxidative preconditioning. ${ }^{*} \mathrm{P}=0.145$ (Kruskall-Wallis test).

studies have so far shown that ozone therapy appears useful in diseases including peritonitis, infected wounds, chronic skin ulcers, initial gangrene, burns, and advanced ischemic diseases (15). Ozone therapy has many modes of application including inhalation, intravenous, intraarterial, subcutaneous, intramuscular, intra-articular, or via enema (16). Repeated rectal administration of ozone has induced a sort of cross-tolerance to free radicals released after hepatic and renal ischemia-reperfusion $(7,17,18)$. It has also been demonstrated that low doses of ozone increased antioxidant endogenous systems involving GSH, SOD, and CAT, preparing the host to face physiopathological conditions mediated by ROS $(5,7,17,18)$. Ozone, probably by means of an oxidative preconditioning mechanism, similar to ischemic preconditioning, protected these organs from the damage produced by ROS, which induced improvement in the antioxidant-prooxidant balance and the concomitant preservation of the cell redox state $(8,9,15)$. On the other

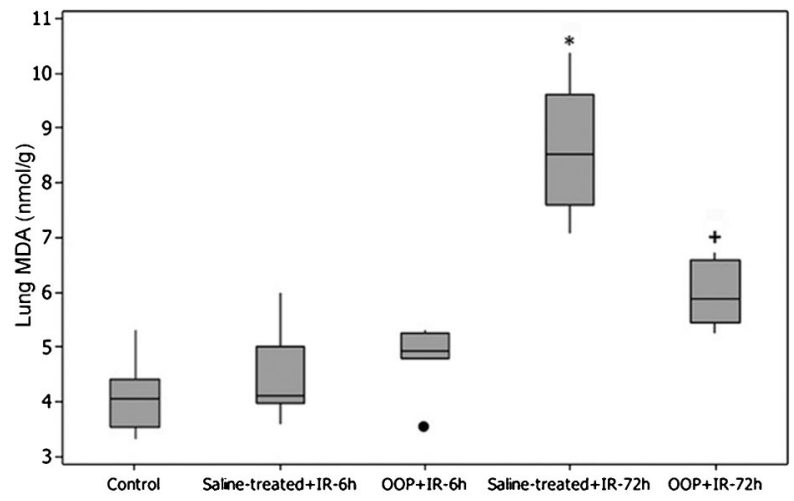

Figure 3. Malondialdehyde (MDA) levels in the lung tissues of control, saline-treated + ionizing radiation (IR), or ozone oxidative preconditioning (OOP) + IR groups decapitated at 6 or $72 \mathrm{~h}$ after irradiation. Each group consisted of 8 rats. Circle: outlier. ${ }^{*} \mathrm{P}=0.001$ compared to control group; ${ }^{+} \mathrm{P}=0.001$ compared to saline-treated group (Mann-Whitney U-test). 


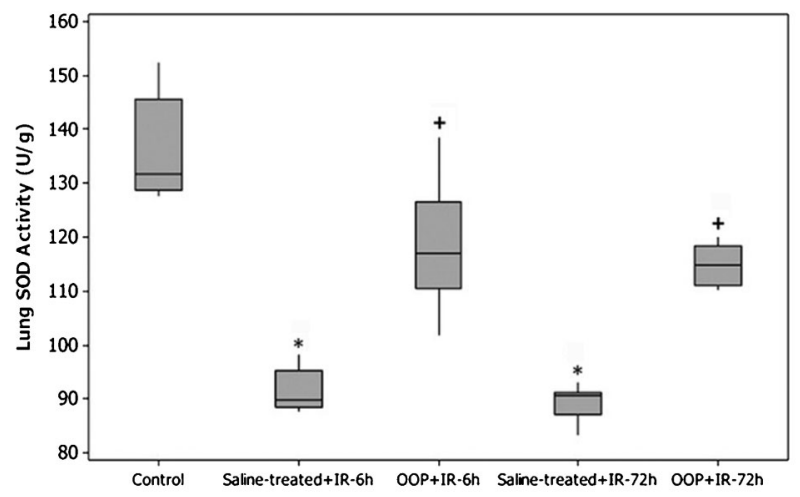

Figure 4. Superoxide dismutase (SOD) activity in the lung tissues of control, saline-treated+ionizing radiation (IR), or ozone oxidative preconditioning (OOP) + IR groups decapitated at 6 or $72 \mathrm{~h}$ after irradiation. Each group consisted of 8 rats. ${ }^{*} \mathrm{P}=0.001$ compared to control group; ${ }^{+} \mathrm{P}=0.001$ compared to saline-treated group (Mann-Whitney U-test).

hand, it is very well known that inhalation of ozone can induce lung injury characterized by inflammation, edema, and altered lung function (19). Ozone, a photochemical air pollutant, is a very potent oxidant and reacts rapidly with biomolecules. The lungs are the most affected organ, and pulmonary surfactant may be a target in ozoneinduced lung toxicity (20). Moreover, toxic effects of ozone caused by excessive doses of inhaled ozone in the airways, as well as toxicity to the endocrine, reproductive, and central nervous systems, have been described $(21,22)$. Although it has been demonstrated that an intrarectal or ip ozone/oxygen mixture reduced ROS by stimulation and/or preservation of the endogenous antioxidant systems in experimental models of liver and renal ischemia-reperfusion and radiationinduced organ injury, respectively $(7,9,17,23,24)$, little is known about its side effects that are specifically related to

Table 4. Tissue SOD levels of control, saline-treated $+I R$, or $\mathrm{OOP}+\mathrm{IR}$ groups decapitated at 6 or $72 \mathrm{~h}$ after irradiation.

\begin{tabular}{lcc}
\hline Groups & \multicolumn{2}{c}{ Median tissue SOD levels } \\
\cline { 2 - 3 } & $\begin{array}{c}\mathrm{U} / \mathrm{g} \\
\text { (min-max) }\end{array}$ & $\begin{array}{c}95 \% \mathrm{Cl} \\
\text { (lower-upper) }\end{array}$ \\
\hline $\begin{array}{l}\text { Control (group 1) } \\
\text { Saline-treated + IR }\end{array}$ & $131.61(127.57-152.32)$ & $129.62-142.45$ \\
$6 \mathrm{~h}$ (group 2) & $89.83(87.68-98.33)$ & $89.14-94.01$ \\
$\begin{array}{l}\text { Saline-treated + IR } \\
72 \mathrm{~h} \text { (group 3) }\end{array}$ & $90.52(83.37-92.94)$ & $87.23-91.40$ \\
$\begin{array}{l}\text { OOP + IR 6 h } \\
\text { (group 4) }\end{array}$ & $117.00(101.89-138.38)$ & $111.48-126.24$ \\
$\begin{array}{l}\text { OOP + IR 72 h } \\
\text { (group 5) }\end{array}$ & $114.79(110.28-120.02)$ & $112.36-117.30$ \\
\hline
\end{tabular}

SOD: superoxide dismutase; IR: ionizing radiation; OOP: ozone oxidative preconditioning. ${ }^{*} \mathrm{P}=0.001$ (Kruskall-Wallis test). free radical formation and irritation of the respiratory system.

Experimental studies have shown that, in the case of RILI, the immediate release of proinflammatory cytokines such as TNF- $\alpha$, IL-1 $\beta$, and IL-6 after IR is closely related to lung toxicity (24). In our study, OOP reduced the release of radiation-induced TNF- $\alpha$ and IL-1 $\beta$. On the other hand, studies have shown that inhalation of ozone induces airway hyperactivity and interacts with airway epithelium and alveolar macrophages to produce inflammation via increasing inflammatory cytokines, including TNF- $\alpha$ and IL-1 $\beta(25,26)$. However, Bette et al. (27) evaluated OOP with ip administration of ozone, followed by a tazobactam/piperacillin regimen in rats submitted to peritonitis, and found an increase in survival rates and a decrease in proinflammatory cytokines, TNF- $\alpha$ and IL-1 $\beta$. Similarly, Zamora et al. (28) observed a significant inhibitory effect of serum TNF- $\alpha$ release on mice pretreated with an ozone/oxygen mixture by the ip route before induction of endotoxic shock by lipopolysaccharides. These results suggest that ip injections of a toxic dose of an ozone/oxygen mixture might modify the production and/or release of TNF- $\alpha$ and IL-1 $\beta$. The inhibitory effects of OOP on TNF- $\alpha$ and IL-1 $\beta$ levels in the serum of irradiated rats might be a consequence of stimulation of antioxidant defenses induced by ozone therapy.

This point of view is scientifically supported by the fact that IR is associated with increased production of free radicals (29), which is reflected by the accumulation of oxidatively damaged cellular macromolecules. Ionizing radiation may impair lung cells either directly via generation of ROS (29) or indirectly via the action on parenchymal and inflammatory cells through biological mediators (30). This process may subordinate the cellular antioxidant defenses and lead to the accumulation of toxic levels of ROS. Our results showed that, at $6 \mathrm{~h}$ after IR, rat pulmonary tissues did not have significantly increased radiation-induced lipid peroxidation. However, lung MDA levels were found to be higher in IR groups at $72 \mathrm{~h}$ compared to the control group, and MDA levels in the group treated with ozone remained unchanged compared to the IR-exposed group. In our study, we found that pulmonary SOD activity values of the rats that received IR were lower than the control group suggesting the existence of oxidative stress in these rats. This is evidence for the relationship between high MDA levels and the occurrence of oxidative stress. In the OOP plus IR group, ozone treatment induced a significant increase in lung SOD activity compared to the radiation only group at $72 \mathrm{~h}$ after TBI. However, studies show that ozone inhalation causes excessive production of cytotoxic mediators including pro-inflammatory cytokines, ROS, and nitrogen intermediates by airway epithelial cells and activated lung immune cells $(31,32)$, Rodriguez et al. (33) demonstrated the efficacy of ip ozone pretreatment in a fecal peritonitis model by means of reducing 


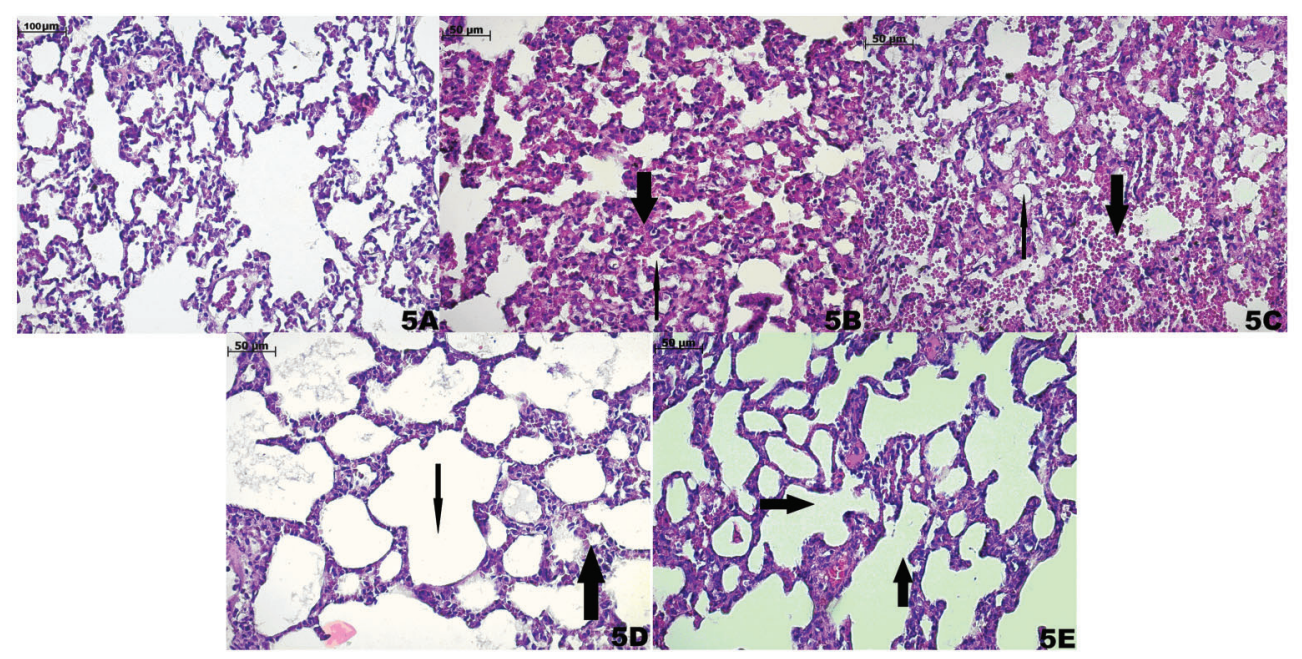

Figure 5. Histopathological findings of the groups. A, Normal lung parenchyma in the control group [hematoxylin-eosin (HE), 100X]. B, Alveolar area reduction (thin arrow) and alveolar hemorrhage (thick arrow) in radiation-treated group at $6 \mathrm{~h}(\mathrm{HE}, 200 \mathrm{X})$. $C$, Severe alveolar hemorrhage (thick arrow), alveolar area reduction (thin arrow), interstitial congestion, and edema in the radiation-treated group at $72 \mathrm{~h}(\mathrm{HE}, 200 \mathrm{X}) . D$, Reduced interstitial congestion and alveolar hemorrhage (thick arrow) and expanded alveolar area (thin arrow) in ozone-treated groups at $6 \mathrm{~h}(\mathrm{HE}, 200 \mathrm{X})$. E, Clearly reduced interstitial congestion and alveolar hemorrhage and re-established alveolar structure (arrows) in ozone-treated groups at $72 \mathrm{~h}$ (HE, 200X).

lung myeloperoxidase activity and serum lipid peroxidation, and increasing antioxidant enzyme activities. Another recent study showed that ip ozone therapy modulated the inflammatory response and acute lung injury resulting from intra-abdominal infection in rats (34).

Therefore, the results of our study suggested that, in contrast with effects of ozone inhalation on lung in different experimental models, OOP in rat lung conferred protection from acute radiation damage. OOP managed this effect by reducing serum levels of TNF- $\alpha$ and IL-1 $\beta$, increasing SOD activity in lung tissue, and prevention of exaggerated lipid peroxidation. Moreover, histological analyses of the lung tissues $72 \mathrm{~h}$ after IR showed acute inflammation, including alveolar area reduction and alveolar and bronchiolar hemorrhage, and, compared with the saline-treated and IR groups, OOP ameliorated RILI. Thus, our data regarding alleviation of RILI by OOP were consistent with the findings of Yamanel et al. (35) in which ozone therapy provided protection against sepsisinduced lung injury as evidenced by increased SOD and GSHPx activities and attenuation of histopathological findings in acute lung injury.

Because it is well established that ozone causes acute airway hyperreactivity after exposure, it should also be stressed that the ip route of administering the oxygen/ozone mixture did not exacerbate RILI, and OOP reduced RILI.

In the present study, it was demonstrated that OOP increased pulmonary SOD activity and attenuated histopathological findings of RILI in rats exposed to TBI. Because TBI decreased the total antioxidant capacity of organisms and the levels of known antioxidants were depleted, the involvement of free radical scavengers to protect against IR damage was highlighted. Recent insights into the mechanism of RILI have shown that a new therapeutic approach is targeted against the continuous production of ROS/reactive nitrogen species in an ongoing process that perpetuates lung injury (36). Therefore, increasing antioxidant capacity may be a strategy to prevent RILI. In animal models, the overexpression of human copper/zinc or manganese SOD genes delivered using liposomes or adenoviral vectors has provided protection against RILI. This effect is probably also mediated through decreased expression of IL-1, TNF, and TGF- $\beta$ (37). Similarly, Rabbani et al. (38) showed that overexpression of extracellular SOD, one of the subtypes of naturally occurring SOD, conferred protection against RILI. Other SOD-mimetic agents have also shown promise in reducing RILI in animal studies (39). Thus, the findings of the present study support OOP as an alternative therapy to attenuate deleterious effects of IR on lung. Moreover, our research team previously presented the benefits of OOP in radiation-induced liver and ileal injury. It was observed that OOP reduced oxidative stress levels and tissue injury in rats exposed to TBI (9). However, in the present study, we did not examine the mechanisms underlying OOP in animal models of RILI, and also no reports have examined the mechanisms underlying OOP in animal models of radiationinduced organ damage. On the other hand, several animal models have been developed to investigate the mechanisms, characteristics, and pathophysiology of OOP $(5-9,11,12,15,17,18,21,27,28,33,34)$. The current evidence indicates that the protective effect of OOP is attributed to induction of antioxidant enzyme gene expression $(5,8,40)$. 
In conclusion, although it seems paradoxical that ozone, a potent oxidant agent, may exert opposite effects and behave as antioxidant agent when it is used at low doses via ip administration, the procedure of OOP has demonstrated convincingly protective and beneficial effects in disorders in which oxidative stress and inflammation are involved, as occurs in RILI. Ozone treatment decreased serum TNF- $\alpha$ and IL-1 $\beta$ levels, increased lung tissue SOD activity, and preserved pulmonary MDA levels. Also the histological findings of

\section{References}

1. Mettler FA Jr, Voelz GL. Major radiation exposure - what to expect and how to respond. N Engl J Med 2002; 346: 15541561, doi: 10.1056/NEJMra000365.

2. Coleman CN, Blakely WF, Fike JR, MacVittie TJ, Metting $\mathrm{NF}$, Mitchell JB, et al. Molecular and cellular biology of moderate-dose (1-10 Gy) radiation and potential mechanisms of radiation protection: report of a workshop at Bethesda, Maryland, December 17-18, 2001. Radiat Res 2003; 159: 812-834, doi: 10.1667/RR3021.

3. Agrawal A, Chandra D, Kale RK. Radiation induced oxidative stress: II studies in liver as a distant organ of tumor bearing mice. Mol Cell Biochem 2001; 224: 9-17, doi: 10.1023/A:1011990704575.

4. Gracy RW, Talent JM, Kong Y, Conrad CC. Reactive oxygen species: the unavoidable environmental insult? Mutat Res 1999; 428: 17-22, doi: 10.1016/S1383-5742(99)00027-7.

5. Hernandez F, Menendez S, Wong R. Decrease of blood cholesterol and stimulation of antioxidative response in cardiopathy patients treated with endovenous ozone therapy. Free Radic Biol Med 1995; 19: 115-119, doi: 10.1016/08915849(94)00201-T.

6. Chen H, Xing B, Liu X, Zhan B, Zhou J, Zhu H, et al. Ozone oxidative preconditioning protects the rat kidney from reperfusion injury: the role of nitric oxide. J Surg Res 2008; 149: 287-295, doi: 10.1016/j.jss.2007.12.756.

7. Leon OS, Menendez S, Merino N, Castillo R, Sam S, Perez $\mathrm{L}$, et al. Ozone oxidative preconditioning: a protection against cellular damage by free radicals. Mediators Inflamm 1998; 7: 289-294, doi: 10.1080/09629359890983.

8. Bocci VA. Scientific and medical aspects of ozone therapy. State of the art. Arch Med Res 2006; 37: 425-435, doi: 10.1016/j.arcmed.2005.08.006.

9. Gultekin FA, Bakkal BH, Guven B, Tasdoven I, Bektas S, Can $\mathrm{M}$, et al. Effects of ozone oxidative preconditioning on radiation-induced organ damage in rats. J Radiat Res 2013; 54: 36-44, doi: 10.1093/jrr/rrs073.

10. Sunil VR, Patel-Vayas K, Shen J, Laskin JD, Laskin DL. Classical and alternative macrophage activation in the lung following ozone-induced oxidative stress. Toxicol Appl Pharmacol 2012; 263: 195-202, doi: 10.1016/j.taap.2012.06.009.

11. Guven A, Gundogdu G, Vurucu S, Uysal B, Oztas E, Ozturk $\mathrm{H}$, et al. Medical ozone therapy reduces oxidative stress and intestinal damage in an experimental model of necrotizing enterocolitis in neonatal rats. J Pediatr Surg 2009; 44: 17301735, doi: 10.1016/j.jpedsurg.2009.01.007.

12. Kesik V, Uysal B, Kurt B, Kismet E, Koseoglu V. Ozone
RILI improved with ozone treatment in rats. However, the major limitation of this study was evaluating the short-term effects of radiation-induced pulmonary toxicity. At the studied dose and administration route, ozone seemed to be of benefit in reducing irradiation-induced oxidative injury of lung tissues. Therefore, further studies are required to identify late effects of OOP. Additional studies using high-dose thoracic radiation will determine whether administration of ozone can prevent radiation-induced pneumonitis and/or fibrotic remodeling in the lung. ameliorates methotrexate-induced intestinal injury in rats. Cancer Biol Ther 2009; 8: 1623-1628, doi: 10.4161/cbt.8. 17.9203.

13. Lowry $\mathrm{OH}$, Rosebrough NJ, Farr AL, Randall RJ. Protein measurement with the Folin phenol reagent. $J$ Biol Chem 1951; 193: 265-275.

14. Sun Y, Oberley LW, Li Y. A simple method for clinical assay of superoxide dismutase. Clin Chem 1988; 34: 497-500.

15. Re L, Mawsouf MN, Menendez S, Leon OS, Sanchez GM, Hernandez F. Ozone therapy: clinical and basic evidence of its therapeutic potential. Arch Med Res 2008; 39: 17-26, doi: 10.1016/j.arcmed.2007.07.005.

16. Eliakim R, Karmeli F, Rachmilewitz D, Cohen P, Zimran A. Ozone enema: a model of microscopic colitis in rats. Dig Dis Sci 2001; 46: 2515-2520, doi: 10.1023/A:1012348525208.

17. Peralta C, Leon OS, Xaus C, Prats N, Jalil EC, Planell ES, et al. Protective effect of ozone treatment on the injury associated with hepatic ischemia-reperfusion: antioxidantprooxidant balance. Free Radic Res 1999; 31: 191-196, doi: 10.1080/10715769900300741.

18. Barber E, Menendez S, Leon OS, Barber MO, Merino N, Calunga JL, et al. Prevention of renal injury after induction of ozone tolerance in rats submitted to warm ischaemia. Mediators Inflamm 1999; 8: 37-41, doi: 10.1080/ 09629359990702.

19. Mustafa MG. Biochemical basis of ozone toxicity. Free Radic Biol Med 1990; 9: 245-265, doi: 10.1016/08915849(90)90035- H.

20. Haagsman HP, van Golde LM. Lung surfactant and pulmonary toxicology. Lung 1985; 163: 275-303, doi: 10.1007/BF02713827.

21. Silva RA, Garotti JE, Silva RS, Navarini A, Pacheco AM Jr. Analysis of the bactericidal effect of ozone pneumoperitoneum. Acta Cir Bras 2009; 24: 124-127, doi: 10.1590/ S0102-86502009000200009.

22. Bhalla DK, Gupta SK, Reinhart PG. Alteration of epithelial integrity, alkaline phosphatase activity, and fibronectin expression in lungs of rats exposed to ozone. J Toxicol Environ Health A 1999; 57: 329-343, doi: 10.1080/009841099157647.

23. Riepe MW, Ludolph AC. Chemical preconditioning: a cytoprotective strategy. Mol Cell Biochem 1997; 174: 249254, doi: 10.1023/A:1006820927262.

24. Shimbo $T$, Inomata $T$, Takahashi $M$, Tatsumi $T$, Uesugi $Y$, Narabayashi I, et al. Effects of sivelestat sodium hydrate on the reduction of radiation pneumonitis. Int J Mol Med 2007; 20: $817-822$ 
25. Arsalane K, Gosset P, Vanhee D, Voisin C, Hamid Q, Tonnel $A B$, et al. Ozone stimulates synthesis of inflammatory cytokines by alveolar macrophages in vitro. Am J Respir Cell Mol Biol 1995; 13: 60-68, doi: 10.1165/ajrcmb.13.1.7598938.

26. Connor AJ, Laskin JD, Laskin DL. Ozone-induced lung injury and sterile inflammation. Role of Toll-like receptor 4. Exp Mol Pathol 2012; 92: 229-235, doi: 10.1016/j.yexmp. 2012.01.004.

27. Bette M, Nusing RM, Mutters R, Zamora ZB, Menendez S, Schulz S. Efficiency of tazobactam/piperacillin in lethal peritonitis is enhanced after preconditioning of rats with $\mathrm{O}_{3} / \mathrm{O}_{2}$-pneumoperitoneum. Shock 2006; 25: 23-29, doi: 10.1097/01.shk.0000187983.56030.dd.

28. Zamora ZB, Borrego A, Lopez OY, Delgado R, Gonzalez R, Menendez S, et al. Effects of ozone oxidative preconditioning on TNF-alpha release and antioxidant-prooxidant intracellular balance in mice during endotoxic shock. Mediators Inflamm 2005; 2005: 16-22, doi: 10.1155/MI.2005.16.

29. Riley PA. Free radicals in biology: oxidative stress and the effects of ionizing radiation. Int J Radiat Biol 1994; 65: 2733, doi: 10.1080/09553009414550041.

30. Rubin P, Johnston CJ, Williams JP, McDonald S, Finkelstein $\mathrm{JN}$. A perpetual cascade of cytokines postirradiation leads to pulmonary fibrosis. Int J Radiat Oncol Biol Phys 1995; 33 : 99-109, doi: 10.1016/0360-3016(95)00095-G.

31. Laskin DL, Fakhrzadeh L, Laskin JD. Nitric oxide and peroxynitrite in ozone-induced lung injury. Adv Exp Med Biol 2001; 500: 183-190, doi: 10.1007/978-1-4615-0667-6 24.

32. Roberts RA, Laskin DL, Smith CV, Robertson FM, Allen EM, Doorn JA, et al. Nitrative and oxidative stress in toxicology and disease. Toxicol Sci 2009; 112: 4-16, doi: 10.1093/ toxsci/kfp179.

33. Rodriguez ZZ, Guanche D, Alvarez RG, Rosales FH, Alonso $Y$, Schulz $S$. Preconditioning with ozone/oxygen mixture induces reversion of some indicators of oxidative stress and prevents organic damage in rats with fecal peritonitis. Inflamm Res 2009; 58: 371-375, doi: 10.1007/s00011-009-0001-2.

34. Souza YM, Fontes B, Martins JO, Sannomiya P, Brito GS Younes RN, et al. Evaluation of the effects of ozone therapy in the treatment of intra-abdominal infection in rats. Clinics 2010 65: 195-202, doi: 10.1590/S1807-59322010000200012.

35. Yamanel L, Kaldirim U, Oztas Y, Coskun O, Poyrazoglu Y, Durusu $\mathrm{M}$, et al. Ozone therapy and hyperbaric oxygen treatment in lung injury in septic rats. Int J Med Sci 2011; 8 : 48-55, doi: 10.7150/ijms.8.48.

36. Vujaskovic Z, Anscher MS, Feng QF, Rabbani ZN, Amin K, Samulski TS, et al. Radiation-induced hypoxia may perpetuate late normal tissue injury. Int J Radiat Oncol Biol Phys 2001; 50: 851-855, doi: 10.1016/S0360-3016(01)01593-0.

37. Epperly MW, Bray JA, Krager S, Berry LM, Gooding W, Engelhardt JF, et al. Intratracheal injection of adenovirus containing the human MnSOD transgene protects athymic nude mice from irradiation-induced organizing alveolitis. Int J Radiat Oncol Biol Phys 1999; 43: 169-181, doi: 10.1016/ S0360-3016(98)00355-1.

38. Rabbani ZN, Anscher MS, Folz RJ, Archer E, Huang H, Chen $\mathrm{L}$, et al. Overexpression of extracellular superoxide dismutase reduces acute radiation induced lung toxicity. BMC Cancer 2005; 5: 59, doi: 10.1186/1471-2407-5-59.

39. Gauter-Fleckenstein B, Fleckenstein K, Owzar K, Jiang C, Batinic-Haberle I, Vujaskovic Z. Comparison of two Mn porphyrin-based mimics of superoxide dismutase in pulmonary radioprotection. Free Radic Biol Med 2008; 44: $982-$ 989, doi: 10.1016/j.freeradbiomed.2007.10.058.

40. Ajamieh HH, Menendez S, Martinez-Sanchez G, Candelario-Jalil E, Re L, Giuliani A, et al. Effects of ozone oxidative preconditioning on nitric oxide generation and cellular redox balance in a rat model of hepatic ischaemiareperfusion. Liver Int 2004; 24: 55-62, doi: 10.1111/j.14783231.2004.00885.x. 